\title{
Lung penetration and patient adherence considerations in the management of asthma: role of extra-fine formulations
}

This article was published in the following Dove Press journal:

Journal of Asthma and Allergy

10 January 2013

Number of times this article has been viewed

\section{Nicola Scichilone \\ Mario Spatafora \\ Salvatore Battaglia \\ Rita Arrigo \\ Alida Benfante \\ Vincenzo Bellia}

Dipartimento di Biomedicina e Medicina Interna e Specialistica, Sezione di Pneumologia, University of Palermo, Palermo, Italy
Correspondence: Nicola Scichilone Dipartimento di Biomedicina e Medicina Interna e Specialistica, Sezione di Pneumologia, University of Palermo, via Trabucco 180, 90I46 Palermo, Italy Tel +390916802655

Fax +39 09I 6882842

Email nicola.scichilone@unipa.it
Abstract: The mainstay of management in asthma is inhalation therapy at the target site, with direct delivery of the aerosolized drug into the airways to treat inflammation and relieve obstruction. Abundant evidence is available to support the concept that inflammatory and functional changes at the level of the most peripheral airways strongly contribute to the complexity and heterogeneous manifestations of asthma. It is now largely accepted that there is a wide range of clinical phenotypes of the disease, characterized primarily by small airways involvement. Thus, an appropriate diagnostic algorithm cannot exclude biological and functional assessment of the peripheral airways. Similarly, achievement of optimal control of the disease and appropriate management of specific phenotypes of asthma should be based on drugs (and delivery options) able to distribute uniformly along the bronchial tree and to reach the most peripheral airways. Products developed with the Modulite ${ }^{\circledR}$ technology platform have been demonstrated to meet these aims. Recent real-life studies have shown clearly that extra-fine fixed-combination inhaled therapy provides better asthma control than non-extra-fine formulations, thus translating the activity of the drugs into greater effectiveness in clinical practice. We suggest that in patients with incomplete asthma control despite good lung function, involvement of the peripheral airways should always be suspected. When this is the case, treatments targeting both the large and small airways should be used to improve asthma control. Above all, it is emphasized that patient adherence with prescribed medications can contribute to clinical success, and clinicians should always be aware of the role played by patients themselves in determining the success or failure of treatment.

Keywords: asthma, small airways, inflammation, quality of life, device

\section{Challenges in management}

In asthmatics, the aim of treatment is to achieve and maintain the best possible control of the disease, defined as absence of symptoms, no exacerbations, and no limitation of activities, together with the best attainable lung function. Several studies in recent years have shown that optimal control of asthma can be obtained in the vast proportion of patients using inhaled steroids alone or in combination with long-acting $\beta 2$-agonists. ${ }^{1-3}$ However, results from experimental studies do not always reflect real-life conditions, and epidemiological studies in the general population clearly show that asthma is far from being adequately controlled. ${ }^{4,5}$ Several possible explanations have been put forward to explain such a failure of asthma control; theoretically, this could reflect underestimation of disease severity by physicians and patients, with consequent use of inadequate medication and a low degree of adherence to treatment. Although possible, it is very unlikely that lack of asthma control would be due to therapy-resistant disease. 
Other disease-related factors should be considered, ie, asthma is envisaged as an inflammatory disorder of the entire bronchial tree, eventually affecting the smallest airways, the involvement of which may remain functionally and clinically silent until features of air trapping and hyperinflation occur. From a pathophysiological perspective, there is increasing evidence of involvement of the peripheral regions of the bronchial tree, and their response to treatment should not be ignored when approaching asthma. It is possible that functional alterations reflecting abnormalities at the level of the peripheral airways are closely associated with lack of asthma control despite conventional treatment.

\section{Role of small airways}

Inflammation in asthma is irregularly distributed throughout the airways, and the smaller airways ( $<2 \mathrm{~mm})$ and the parenchyma are also involved. This evidence has important implications, ie, delivery of inhaled medications to appropriate areas of the lung is mandatory for successful treatment of asthma.

The role of the peripheral airways in asthma is increasingly being recognized as a potential target for achievement of optimal control of the condition. ${ }^{4-6}$ Studies based on imaging, transbronchial biopsies, and autopsy specimens have confirmed the role of the peripheral airways in severe or fatal asthma. ${ }^{7-12}$ The ENFUMOSA (European Network for Understanding Mechanisms of Severe Asthma) project, a cross-sectional, observational study of severe asthmatics versus not severe asthmatics, identified air trapping, a functional abnormality that is attributed to changes in the peripheral airways, as contributing to the pathogenesis of severe asthma. ${ }^{13}$ An observational study ${ }^{14}$ comparing severe and nonsevere asthmatics confirmed previous observations by showing that forced vital capacity, used as a physiological measure of air trapping, was significantly reduced at any level of airways obstruction. In this group of asthmatics, changes in the peripheral airways could be envisaged as the primary pathogenetic mechanism, characterizing a condition of excessive bronchoconstriction and more severe clinical features. Following this reasoning, identification of this phenotype would advocate for an appropriate targeted treatment.

The importance of the peripheral airways in the management of asthma could also lie in the assessment and prevention of future risk. Future risk refers to exacerbations, loss of control, a faster rate of decline in lung function, and side effects of treatment. In this scenario, the detection of small airway abnormalities could indicate patients at major risk of asthma attacks or more severe disease, and predict those likely to benefit from a specific intervention. These observations also imply that functional or pathophysiological parameters reflecting small airways involvement might be used prognostically.

In the context of small airways involvement in specific phenotypes of asthma, it is worth noting that, in a recent study by Scichilone et al, ${ }^{15}$ the beneficial effect of an intensive course of exercise training in asthmatics primarily occurred at the level of the peripheral airways. The authors found that the response to methacholine in a protocol devoid of deep inspiratory maneuvers was more evident in terms of attenuation of airway closure and lung hyperinflation, which reflects changes in the small airways. The mechanism by which intensive training exercise reduces airway hyperresponsiveness lies in the distending effect of lung inflation on the airways, which mainly occurs at the level of the peripheral airways. ${ }^{16}$ By virtue of airway-to-parenchyma interdependence, deep inspirations eventually cause lengthening or stretching of smooth muscle in the airways and may induce a reorganization of the contractile apparatus, thus reducing the airway response to spasmogens. ${ }^{17}$

\section{Lung penetration and role of extra-fine formulations}

The key point in the treatment of asthma by inhaled medication is to reach the target site. This can be obtained by complying with three conditions: the drug delivery system should assure generation of an aerosol cloud containing particles able to penetrate into the respiratory tract; the aerosol formulation should enable the drug to deposit along the respiratory tract; and deposition of the drug should translate into functional and clinical benefits. Drug penetration and deposition in the airways depends on the type of device used, the aerosol formulation, and the patient's inhalation technique. The aerodynamic size of a particle is the principal determinant of its ability to deposit in the lung. Particle size is usually expressed as mass median aerodynamic diameter, and values of $1-5 \mu \mathrm{m}$ are suitable for pulmonary delivery. Using monodispersed albuterol with particle sizes of 1.5, 3.0, and $6 \mu \mathrm{m}$, Usmani et $\mathrm{al}^{18}$ demonstrated on the basis of radioaerosol deposition (gamma scintigraphy) that smaller particles achieve greater total lung and more peripheral deposition. Over the years, many devices have been designed, differing in terms of their technical design (required inspiratory flow rate, actuation), composition (characteristics of propellant, carrier substances), dose per inhalation, and costs. In suspension formulations, the active drug is not soluble in the propellant and therefore remains in solid powder form in the container. 
To improve the homogeneity of the concentration of drug and, consequently, the emission of a constant amount of drug in the various doses, formulations in suspension must be shaken until uniformity of distribution within the canister is reached before use. This is often overlooked by patients, and is one of the most common errors in daily practice. In addition, suspension formulations may release large particles (due to agglomeration of micronized particles) and, in general, only $10 \%-15 \%$ of the total dose reaches the conductive and lower airways. Moreover, suspension formulations need to be delivered with a relatively larger orifice diameter to avoid its blocking by the suspension emitted, which leads to higher velocity and a lower duration of the aerosol plume. Coordination between inhalation and actuation of the device is often not achieved, causing deposition of the larger particles in the oropharynx.${ }^{19}$ Replacement of chlorofluorocarbon propellants with hydrofluoroalkane has allowed, in some cases, a shift to solution formulations, in which the drug is uniformly distributed, so shaking of the inhaler is no longer critical. The new hydrofluoroalkane solution aerosols allow for the particle size to be modified within the respirable range (extra-fine or coarser particles), thus allowing deeper penetration of the medication into the lung (Figure 1). Modulite ${ }^{\circledR}$ technology (Chiesi Farmaceutici, Parma, Italy) has been developed for optimal delivery of inhaled drugs to the lung. ${ }^{20,21}$ This ambitious target could be achieved with integration of device characteristics, propellant characteristics, drug formulation, and appropriate use by patients. With regard to device and propellant characteristics, the goal is to generate a slow moving cloud containing particles of the required particle size. Modulite technology achieves this goal primarily by the geometry of the actuator orifice and careful selection of the hardware. In addition, changes in vapor pressure by mixing available propellants and the volume of the metering valve also contribute to optimize delivery.

The Modulite also uses an appropriate drug concentration and a nonvolatile component to provide the targeted particle size (Figure 2). Indeed, the particle size depends on the drug concentration in a droplet and other nonvolatile components that are added; each droplet will eventually dry to result in a particle, the size of which depends on the concentration of drug in the solution. The actuator geometry also influences the cloud formation, with a smaller orifice producing a more refined spray. Moreover, the use of small pre-established orifices generates slow moving clouds over a much longer time period, helping patients to coordinate the inspiratory maneuver with generation of the cloud. Taken together, these characteristics enable the Modulite technology to deliver drug particles within a desired range of mass median aerodynamic diameter which can reach both the large and small airways. ${ }^{20,21}$ In summary, the Modulite technology is an effective replacement for chlorofluorocarbon-based drug delivery systems, combining ease of use of a pressurized metered-dose inhaler (MDI) with the accuracy of dry powder inhaler dosing. In addition to the option of providing a seamless transition from chlorofluorocarbons to nonchlorofluorocarbon alternatives, this technology has the advantage of enabling the size and distribution of particles to be modulated in order to target the small airways.

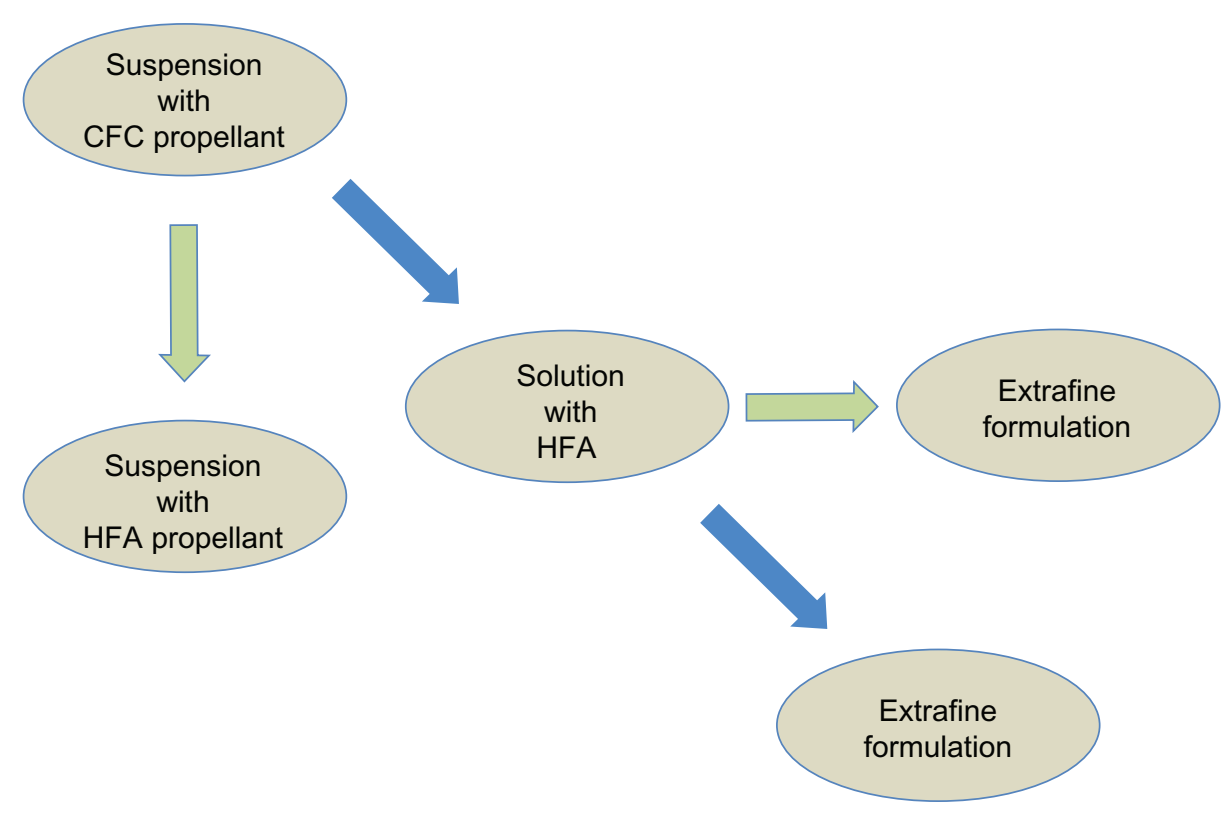

Figure I Algorithm showing the switch from chlorofluorocarbon (CFC) to hydrofluoroalkane (HFA) propellants and development of extra-fine formulations. 


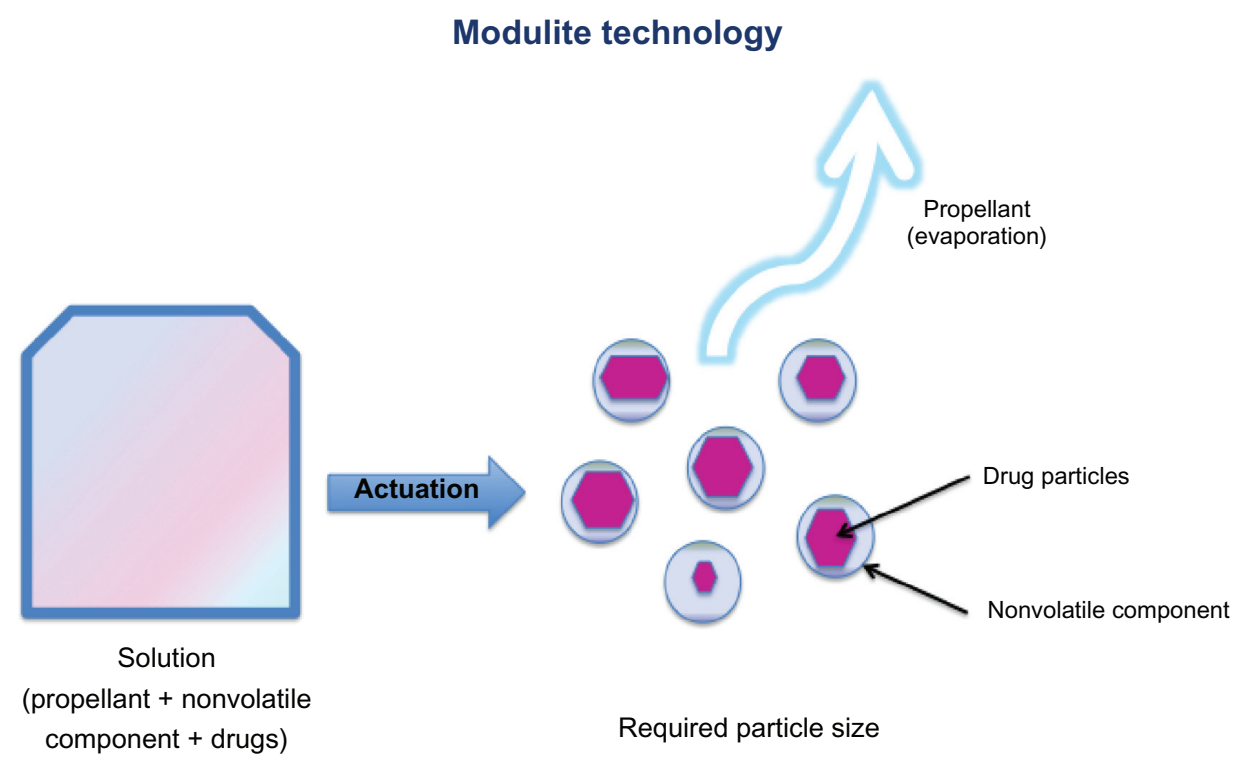

Figure 2 Description of the Modulite ${ }^{\circledR}$ technology (see text for details).

Other devices available include the breath-activated pressurized MDI which is triggered by the inspiratory maneuver (breath-actuated pressurized MDI), whereby the drug is released when inhalation triggers the MDI, and avoids any coordination issues. Finally, the dry powder inhalers, such as the Diskus, Turbuhaler, Diskhaler, and Rotahaler, contain powdered drug that is dispersed into particles after activation by an inspiratory maneuver on the part of the patient. While the pressurized MDIs are all quite similar in terms of their mode of use, dry powder inhalers differ from one to another, and may require completely different actions to be used. Given that dry powder inhalers are breath-actuated, they do not need any coordination between activation and inhalation. Some studies have shown that use of dry powder inhalers may be easier to learn than for MDIs, ${ }^{22,23}$ although the common experience in real life results in conflicting results, eg, they may be managed incorrectly by patients, resulting in a poor level of disease control. We believe that differences in efficacy are trivial when these different devices are used with proper inhalation technique. The issue remains as to whether the targeted site is reached by drug delivered using different devices.

\section{Safety and efficacy studies with extra-fine formulations}

Clinical studies suggest that extra-fine formulations are able to deliver inhaled drugs throughout the whole bronchial tree and can be effective with regard to functional and biological parameters. Accessing and treating the distal part of the lung has recently been reviewed by Scichilone et al. ${ }^{24}$ To date, there are three single-agent extra-fine formulations on the market (beclomethasone, ciclesonide, formoterol), and only one fixed-combination product is available (beclomethasoneformoterol), although a Phase II randomized controlled trial of a fixed combination of ciclesonide-formoterol formulated as a powder has recently been published. ${ }^{25}$ The fine particle fraction of this new powder formulation is approximately $50 \%$ smaller than that in the ciclesonide hydrofluoroalkane MDI. ${ }^{25}$ These formulations are able to deliver particles to both the large and small airways, resulting in a significant increase in drug deposition in the peripheral airways with respect to the dose delivered. ${ }^{26}$ However, this physicomechanical characteristic per se does not imply any clinical advantage. Clinical trials $\mathrm{s}^{27,28}$ have been designed to explore whether use of extra-fine formulations improve lung function, asthma control, and health-related quality of life compared with inhaled drugs delivered as non-extra-fine formulations. Studies of extra-fine inhaled corticosteroids (ICS) have demonstrated larger improvements in functional and inflammatory parameters related to small airways abnormalities compared with non-extra-fine formulations, ${ }^{27,28}$ even at lower extra-fine ICS doses. ${ }^{29}$

Additional studies have extended these observations to a fixed combination of extra-fine beclomethasone-formoterol. A large multicenter, multinational, randomized, controlled Phase III trial ${ }^{30}$ comparing the beclomethasone-formoterol fixed extra-fine combination with the same two drugs given via separate inhalers and in non-extra-fine formulation demonstrated a significantly higher percentage of days with asthma control in the extra-fine combination arm. 
The fixed extra-fine formulation was noninferior in terms of improvement in lung function to fixed non-extra-fine combinations of other inhaled ICS + long-acting $\beta 2$-agonist (LABA) combinations, namely budesonide-formoterol and fluticasone-salmeterol. ${ }^{31,32}$ Recently, Papi et al ${ }^{33}$ demonstrated that in patients whose asthma was controlled with high-dose fluticasone-salmeterol, stepping down to a medium dose of an extra-fine beclomethasone-formoterol combination preserved complete control of symptoms.

As expected, the effect of extra-fine ICS-LABA combinations on functional parameters specifically related to peripheral airways abnormalities ${ }^{31,34}$ is greater than that of non-extra-fine ICS-LABA combinations. In another study reported by Papi et al, ${ }^{31}$ treatment with the extrafine beclomethasone-formoterol combination was significantly superior to an equipotent dose of the non-extra-fine fluticasone-salmeterol combination in terms of improving air trapping, as demonstrated by a reduction in forced vital capacity. The extra-fine beclomethasone-formoterol combination demonstrated a greater and more specific effect on variables directly related to small airways function, as demonstrated by the tendency to be significantly superior to equipotent doses of non-extra-fine fluticasone-salmeterol in improving closing capacity, measured by the single breath nitrogen washout test (Figure 3, $P=0.08$ versus baseline for beclomethasone-formoterol), whereas conventional spirometric parameters showed significant improvements in both treatment arms, ${ }^{34}$ suggesting that the effects of the extra-fine formulation could be attributed to an additional effect on the small airways. In the same study, ${ }^{34}$ a greater (and statistically significant) effect in increasing the provocative concentration of methacholine causing a $20 \%$ fall in forced expiratory volume in one second was documented in the extra-fine formulation arm, suggesting homogeneous distribution of the drug throughout the bronchial tree. The clinical significance of these findings is yet to be determined.

Imaging studies ${ }^{35,36}$ further support the concept that these new formulations produce beneficial changes in the distal airways. Small airways patency has been assessed indirectly by a thoracic high-resolution computed tomography technique for measuring changes in regional hyperinflation, ${ }^{35}$ and ultrafine beclomethasone in hydrofluoroalkane demonstrated greater efficacy than beclomethasone in chlorofluorocarbon in reducing regional air trapping, as assessed by changes in the regional distribution of lung attenuation. Ciclesonide, delivered as a small particle, is also able to reduce small airway inflammation, as showed by Cohen et al, ${ }^{36}$ who demonstrated in a small pilot study that treatment with smallparticle ciclesonide significantly reduces methacholineinduced air trapping due to small airway closure compared with placebo.

It is worth pointing out that reaching the periphery of the lung is not only possible using non-extra-fine combinations, and that budesonide-formoterol delivered by Turbuhaler significantly improves small airways impairment in asthmatic patients compared with fluticasone-salmeterol. ${ }^{37}$ However, peripheral deposition of an extra-fine beclomethasoneformoterol combination is several times higher compared with a non-extra-fine combination. ${ }^{38}$ Moreover, the lung deposition and lung distribution pattern of beclomethasone-formoterol in a pressurized MDI containing hydrofluoroalkane has been compared in asthmatic subjects and healthy controls, using a

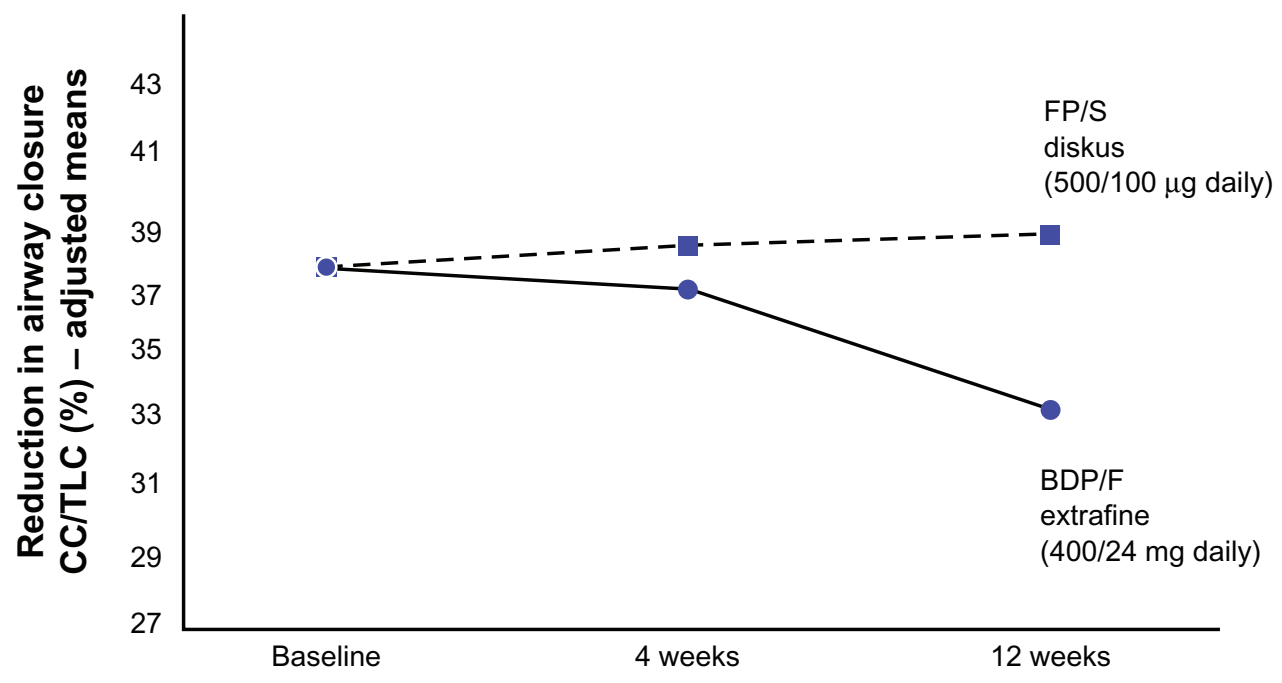

Figure 3 Changes in closing capacity measured by the single-breath nitrogen washout test in the two study groups.

Note: The improvement is greater in the extra-fine beclomethasone-formoterol combination group than in the non-extra-fine fluticasone propionate-formoterol group. Abbreviations: CC/TLC, closing capacity/total lung capacity; FP/S, fluticasone propionate/salmeterol; BDP/F, beclomethasone dipropionate/formoterol. 
formulation labeled with technetium- $99 \mathrm{~m} .{ }^{39}$ Deposition into the lungs showed low variability $(31 \%-34 \%$ of the nominal dose) between asthmatic and healthy subjects, confirming efficient delivery to the lung regardless of pathophysiological conditions. Furthermore, drug distribution was observed throughout the lung, including the peripheral airways, where at least one-third of the drug was deposited (34\% in asthmatic patients and $41 \%$ in healthy subjects), indicating that increased airway obstruction in patients had a moderate impact on the pattern of deposition. ${ }^{39}$ Very recently, the first extra-fine fixed combination of beclomethasone-formoterol inhaled from a proprietary innovative dry powder inhaler called the NEXThaler ${ }^{\circledR}$ has been developed. This extra-fine powder, multidose, breath-actuated inhaler incorporates a novel full dose feedback system providing accurate dose metering and consistent full dose release independent of respiratory flow. The currently available fixed ICS-LABA combinations delivered through dry powder inhalers have a mass median aerodynamic diameter higher than $2 \mu \mathrm{m}$, and are not able to deliver extrafine doses with a MMAD lower than $2 \mu \mathrm{m} .{ }^{40}$ Therefore, the extra-fine fixed combination of beclomethasone-formoterol represents the only extra-fine combination in both pressurized MDI and dry powder inhalers developed so far (Figure 4). ${ }^{40-42}$ A scintigraphic study confirmed high lung deposition (56\% of the emitted dose in asthma patients) and uniform distribution throughout the entire bronchial tree, with a distribution pattern showing one third of the drug deposited in the small airways and two thirds in the large airways (Figure 5). This study involved healthy subjects and patients with asthma or chronic obstructive pulmonary disease, and showed that this effective delivery to the lung was independent of the pathophysiological condition. ${ }^{43}$
The issue is whether improvements in parameters related to small airways function translate into improvements in respiratory symptoms and health-related quality of life. In this respect, extra-fine beclomethasone significantly improved health-related quality of life at 12 months compared with non-extra-fine beclomethasone in a nonblinded, randomized trial of 473 asthmatics, ${ }^{44}$ although this observation needs to be confirmed. This report opens up a different scenario: the beneficial effect on the large airways masks the contribution of changes in the small airways to symptomatic improvement; changes at the level of the small airways mostly affect other clinical or functional features, such as exercise tolerance or exercise-induced dynamic lung hyperinflation; and/or changes in small airway function, primarily lung hyperinflation, could occur during induced or spontaneous bronchoconstriction rather than in stable asthma. Despite the evidence that extra-fine formulations are able to target the peripheral airways, the relative contribution of modulation of peripheral airways abnormalities to clinical outcomes is still unclear, and randomized controlled studies of extra-fine versus non-extra-fine formulations are needed to evaluate whether changes in abnormalities of the small airways correlate with improvement in clinical outcome.

As stated above, demonstration of the efficacy of extrafine formulations in clinical trials does not necessary translate into effectiveness of the same formulation in clinical practice. Development (and constant updating) of guidelines for asthma management is based on major randomized controlled trials, which represent the most rigorous method for assessment of the existence of a cause-effect relationship between treatment and outcome, and to assess the actual cost of treatment. In these studies, enrolled subjects are

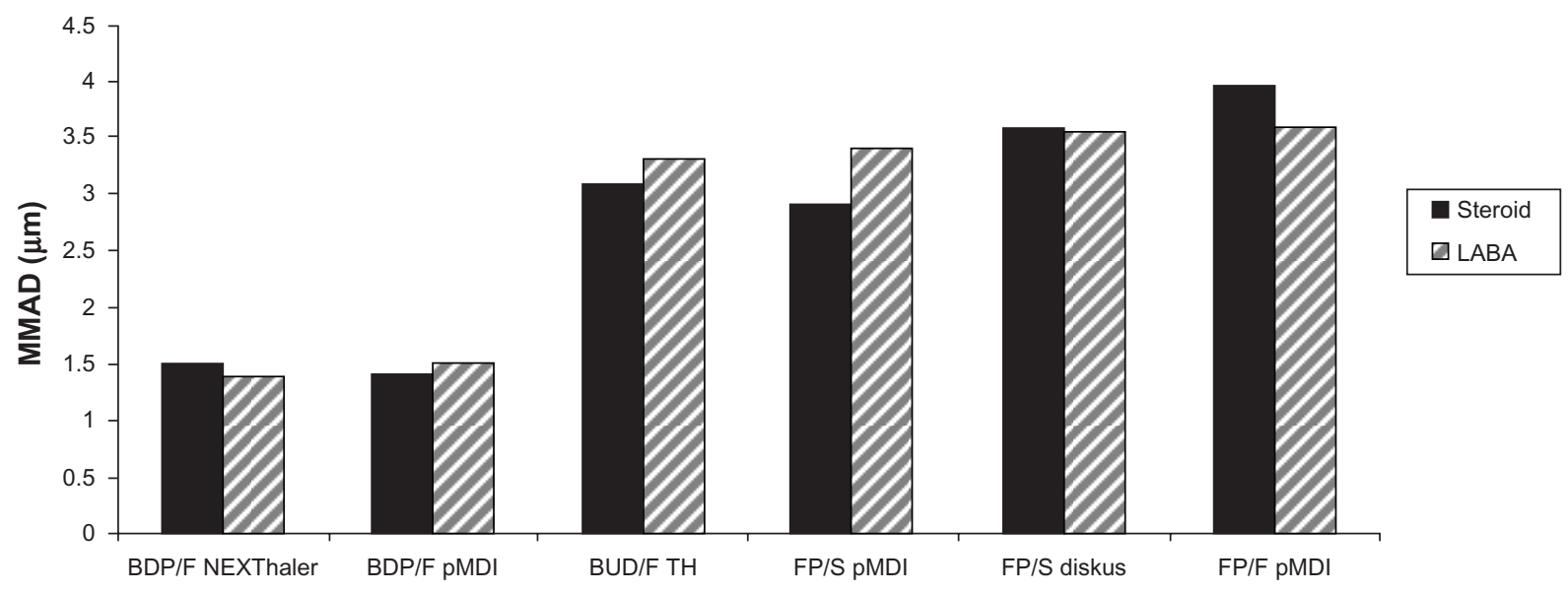

Figure 4 Mass median aerodynamic diameter of inhaled corticosteroids + long-acting $\beta 2$-agonist combinations.

Abbreviations: BDP/F, beclomethasone dipropionate-formoterol; BUD/F, budesonide-formoterol; FP/S, fluticasone propionate-salmeterol; FP/F, fluticasone propionateformoterol; pMDI, pressurized metered-dose inhaler; TH, Turbuhaler ${ }^{\circledR}$; MMAD, mass median aerodynamic diameter; LABA, long-acting beta2 agonist. 


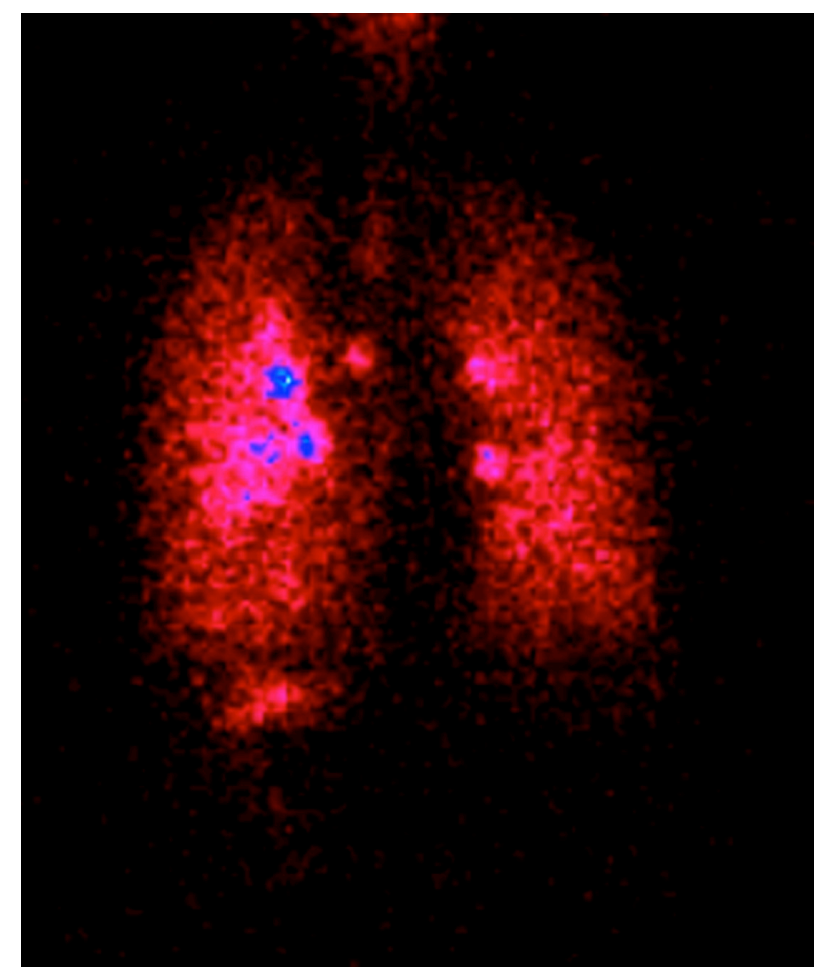

Figure 5 Scintigraphic image in a patient with asthma after inhalation of extra-fine beclomethasone dipropionate-formoterol $400 / 24 \mu \mathrm{g}$ through the NEXThaler ${ }^{\mathrm{TM}}$ dry powder inhaler.

randomly assigned to different groups, which are balanced for the main anthropometric and functional or clinical characteristics, receiving different treatments (ie, active treatment versus placebo or experimental therapy versus conventional therapy). These randomized controlled trials are usually performed in a single-blind or double-blind fashion in order to minimize the influence of external factors on the results (bias). Despite the undeniable usefulness of randomized controlled trials in medical research, some concerns are raised as to the usefulness of the findings that are obtained. One of the most important criticisms lies in the ability to generalize the results of these studies to the general population, which is known as external validity. This is strongly and negatively influenced by rigorous inclusion criteria, which discriminate between the study population and the real-life population. It follows that, in order to achieve high internal validity, the randomized controlled trial is only partially representative of the general population.

In recent years, observational real-life studies ${ }^{45-47}$ have been carried out to verify whether, and in what proportion of patients, asthma control is achieved with currently available (and actually prescribed) therapies. These studies, especially those performed in large populations, are useful to confirm the findings from randomized controlled trials by assessing treatment effectiveness and safety in patients encountered in daily clinical practice. Therefore, these studies may help, with indirect evidence, in understanding whether improvements in small airways function can translate into clinically significant patient outcomes. A study of 111 asthmatics with moderate or severe persistent asthma ${ }^{45}$ showed that $56.6 \%$ of those treated with a fixed extra-fine combination of beclomethasone-formoterol achieved asthma control, as opposed to only $36.2 \%$ of those treated with a fixed nonextra-fine combination of ICS-LABA. A larger multicenter Italian study, PRISMA (PRospectIve Study on asthMA control) ${ }^{46}$ confirmed and extended these initial observations. The PRISMA study included a total of 2853 asthmatic patients, of whom $83.2 \%$ regularly used pharmacological therapy for asthma. Patients treated with a fixed extra-fine combination of beclomethasone-formoterol achieved better asthma control and quality of life than those using other fixed non-extra-fine combinations of ICS-LABA. Although this observational study cannot provide scientific proof to explain these results, it is plausible to postulate that the improvement in asthma control was achieved by the smaller particle sizes in the extra-fine beclomethasone-formoterol combination compared with larger particles of other fixed non-extrafine combinations, enabling the ICS-LABA to reach and treat both large and small airways effectively. Moreover, another recent real-life study ${ }^{47}$ investigated a population of asthmatics who smoked, a not uncommon subgroup of asthmatics who are, by definition, excluded from randomized controlled trials in asthma. In the cohort of smokers, lung function improved significantly, and all comparisons between smokers and nonsmokers in terms of measures of effectiveness (lung function and asthma control) did not reveal any significant difference in therapeutic response to extra-fine beclomethasone-formoterol. Therefore, this study confirmed the effectiveness of beclomethasone-formoterol in current clinic practice, thus extending the indication of extra-fine beclomethasone-formoterol to treat patients with moderate to severe persistent asthma who smoke.

A direct consequence of asthma control should be improvement in health-related quality of life. Initial observations demonstrated that switching from a non-extra-fine formulation to an extra-fine one containing the same ICS (beclomethasone) significantly improved health-related quality of life, although conventional clinical indices of pulmonary function did not differ. ${ }^{44}$ More recently, relationships between small airways function and patient-reported outcomes of health status, dyspnea, and disease control have been assessed. ${ }^{48}$ The findings demonstrated that peripheral 
airways function (assessed by impulse oscillometry) in addition to proximal airways function were correlated with the above-mentioned outcomes. Larger and more specifically designed controlled trials are required to clarify and confirm this relationship. Table 1 summarizes the main results of studies comparing the beclomethasone-formoterol combination with other fixed-dose combinations.

\section{Patient adherence considerations}

The contribution of patient adherence with prescribed medication to clinical success cannot be overestimated, ${ }^{49}$ and clinicians should always be aware of the role played by patients themselves in determining the success or failure of treatment. Indeed, in many cases, the problem does not lie with the medication, but in whether or not the patient is properly exposed to it. These general concepts apply perfectly to asthma, the management of which is based on the use of inhalation therapy. The clinical benefit provided by inhaled therapy can be influenced by several factors, mostly related to the patient rather than to the medication itself. ${ }^{50}$ Amongst these, adherence plays a major role, particularly in pediatric and elderly patients. "Adherence" must be distinguished from "compliance", the main difference being related to the agreement of the patient to take the prescription. Hence, while "noncompliant" patients simply ignore prescriptions, adherent patients consistently take medications as prescribed and nonadherent ones fail to do so, despite their positive attitude to the prescription. Three forms of nonadherence have been identified, ie, erratic, unwitting, and deliberate..$^{51}$
Erratic nonadherence is defined as underuse of medications, missed doses, and drug "holidays", which are all conditions that typically occur in children and adolescents. ${ }^{52}$ The clinical variability of asthma makes the disease particularly prone to erratic adherence. Unwitting or unintentional nonadherence occurs when a patient or a parent of a pediatric patient is nonadherent due to poor understanding of the disease and its treatment. This may occur when a patient does not know the proper technique for inhaler use or does not understand the difference between a rescue and controller medication. This may explain why reduced adherence is more common with $\mathrm{ICS}^{53}$ than with bronchodilators, the inhalation of which is followed by prompt symptomatic relief. Deliberate nonadherence refers to a situation, mainly occurring during periods of disease quiescence, in which treatment is deliberately modified by patients (or parents) who believe that risks of treatment outweigh the benefits.

The issue of patient age is particularly important in unintentional nonadherence. Young children are dependent on others for delivery of medication, and are frequently unable to communicate their perception of symptom severity. ${ }^{54}$ While adolescents tend to underestimate the importance of preventive medicine (ie, taking medications to reduce risk despite being currently well), they are typically exposed to risky behaviors (including tobacco, alcohol, and drug use) and depression, that may undermine asthma management and control through increased medication nonadherence. ${ }^{55}$ In elderly patients, unintentional nonadherence with inhalation therapy represents a complex problem that may lead to significant impairment of symptomatic control of asthma.

Table I Studies comparing the beclomethasone-formoterol combination with the other fixed-dose combinations

\begin{tabular}{|c|c|c|c|}
\hline Reference & Study design & Treatments and daily dose & Results \\
\hline Papi et $\mathrm{al}^{31}$ & Double-blind RCT & $\begin{array}{l}\text { Extra-fine BDP/F }(400 / 24 \mu \mathrm{g}) \text { versus } \\
\text { FP/S }(500 / 100 \mu \mathrm{g})\end{array}$ & $\begin{array}{l}\text { Greater FVC change from baseline with extra-fine BDP/F } \\
\text { as compared with FP/S }(P=0.040)\end{array}$ \\
\hline Huchon et a ${ }^{30}$ & $\begin{array}{l}\text { Double-blind, double- } \\
\text { dummy, RCT }\end{array}$ & $\begin{array}{l}\text { Extra-fine BDP/F }(400 / 24 \mu \mathrm{g}) \text { versus } \\
\mathrm{BDP}+\mathrm{F}(1000 / 24 \mu \mathrm{g})\end{array}$ & $\begin{array}{l}\text { Greater percentage of asthma control days with extra- } \\
\text { fine BDP/F as compared with } B D P / F(P<0.005)\end{array}$ \\
\hline Scichilone et a ${ }^{34}$ & $\begin{array}{l}\text { Double-blind, double- } \\
\text { dummy, RCT }\end{array}$ & $\begin{array}{l}\text { Extra-fine BDP/F }(400 / 24 \mu \mathrm{g}) \text { versus } \\
\text { FP/S }(500 / 100 \mu \mathrm{g})\end{array}$ & $\begin{array}{l}\text { Significant improvement from baseline of } \mathrm{PD}_{20} \mathrm{MchFEV} \text {, was } \\
\text { observed only with extra-fine BDP/F and not with FP/S }\end{array}$ \\
\hline Müller et $\mathrm{a}^{45}$ & $\begin{array}{l}\text { Real-life observational } \\
\text { study }\end{array}$ & $\begin{array}{l}\text { Extra-fine BDP/F (mean daily BDP } \\
\text { dose } 312 \mu \mathrm{g} \text { ) versus BUD/F } \\
\text { (mean daily BDP dose } 590 \mu \mathrm{g} \text { ) } \\
\text { and FP/S (mean daily FP dose } 675 \mu \mathrm{g} \text { ) }\end{array}$ & $\begin{array}{l}\text { Significantly higher percentage of patients with controlled } \\
\text { asthma with extra-fine BDP/F as compared with } \\
\text { BUD/F + FP/S }(P=0.03 I) \text {; significantly better asthma } \\
\text { control total score, daytime symptom score and rescue } \\
\text { medication use score with extra-fine BDP/F as compared } \\
\text { with BUD/F + FP/S }(P<0.05)\end{array}$ \\
\hline Allegra et $\mathrm{al}^{46}$ & $\begin{array}{l}\text { Real-life observational } \\
\text { study }\end{array}$ & $\begin{array}{l}\text { Extra-fine BDP/F (mean daily BDP } \\
\text { dose } 32 I \mu \mathrm{g} \text { ) versus BUD/F } \\
\text { (mean daily BUD dose } 7 / 5 \mu \mathrm{g} \text { ) } \\
\text { and FP/S (mean daily FP dose } 720 \mu \mathrm{g} \text { ) }\end{array}$ & $\begin{array}{l}\text { Significantly higher percentage of patients with controlled } \\
\text { asthma with extra-fine BDP/F as compared with BUD/F } \\
(P=0.032) \text { and significantly higher quality of life with } \\
\text { extra-fine BDP/F as compared with FP/S }(P=0.018)\end{array}$ \\
\hline
\end{tabular}

Abbreviations: $\mathrm{RCT}$, randomized controlled trial; BDP/F, beclomethasone-formoterol; FP/S, fluticasone-salmeterol; FVC, forced vital capacity; BUD/F, budesonide/formoterol; $\mathrm{PD}_{20}$ MchFEV $_{1}$, provocative dose of methacholine causing $20 \%$ reduction in forced expiratory volume in one second; BUD, budesonide; BDP, beclomethasone; FP, fluticasone. 
Elderly patients often suffer from several chronic diseases requiring multiple medications. Indeed, complexity of treatment can be considered a major risk factor for reduced adherence with medication, as well as morbidity and mortality in elderly patients. In addition, elderly patients may suffer from cognitive, hearing, or visual impairments, or other physical inabilities (such as arthritis, tremor, and low coordination) that significantly affect their ability to understand and follow treatment regimens.

In a real-life scenario, the characteristics of the extrafine combinations may be helpful to some patients for several reasons: first, the slower velocity and longer duration of the plume may facilitate hand-breath coordination, thereby improving the patient's ability to use the device correctly; in addition, the solution formulation eliminates the need to shake the device before inhalation, which is mandatory for suspensions and is commonly overlooked by patients, resulting in variable dose delivery; and although higher adherence with treatment is expected with all fixed ICS-LABA combinations because of use of a single inhaler, extra-fine beclomethasone-formoterol has demonstrated significant improvements in asthma control as compared with the same drugs administered by separate inhalers ${ }^{32}$ and with non-extra-fine fixed combinations in real-life settings. ${ }^{48}$ Taken together, these observations allow us to hypothesize that extra-fine ICS-LABA combinations contribute to improved adherence with treatment in patients with asthma. It should also be mentioned that the lower nominal dose of ICS, as a result of the improved drug delivery of the extra-fine formulation, results in higher safety, thus contributing to improve adherence further. Obviously, reduction in the amount of drug deposited in the oropharynx limits local side effects of ICS, such as hoarseness, dysphonia, and candidiasis, which are among the major causes of nonadherence.

It must be recognized that patient education is critical for reducing nonadherence and for increasing the overall effectiveness of inhalation therapy for asthma. In this regard, while international guidelines recommend that training sessions should be provided at each visit and that patients should be encouraged to bring all their inhalers to each visit to confirm demonstration of competence in inhalation technique, a consensus is lacking as to how to match incompetence with the criteria to be adopted to choose among the different inhaler devices. In this context, attention should always be paid to patient preference, and the term "adherence to inhalation therapy" should be changed to "therapeutic alliance" between patients and health care providers.

\section{Conclusion}

In conclusion, description of specific asthma phenotypes in which abnormalities of the small airways may play a relevant role would identify groups of patients for whom an extra-fine formulation may represent a specific first-choice therapeutic option, but randomized controlled studies are needed to confirm the relevance of this treatment approach. We anticipate that identifying parameters that selectively reflect peripheral airways dysfunction would appear to be the best way to identify individuals with poorly controlled asthma who will derive little benefit from increasing doses of inhaled treatment, need treatment with extra-fine formulations, or be classified as nonresponders to treatment. When managing cases of difficult-to-treat asthma, we propose that physicians perform lung function assessments to classify the severity of asthma, and assess peripheral airways function and inflammation to detect involvement of this site, in order to make individualized therapeutic decisions and formulate prognostic hypotheses.

\section{Disclosure}

The authors report no conflicts of interest in this work.

\section{References}

1. Bateman ED, Boushey HA, Bousquet J, et al. Can guideline-defined asthma control be achieved? The Gaining Optimal Asthma ControL study. Am J Respir Crit Care Med. 2004;170(8):836-844.

2. O'Byrne PM, Barnes PJ, Rodriguez-Roisin R, et al. Low dose inhaled budesonide and formoterol in mild persistent asthma: the OPTIMA randomized trial. Am J Respir Crit Care Med. 2001;164(8 Pt 1): 1392-1397.

3. Rabe KF, Atienza T, Magyar P, Larsson P, Jorup C, Lalloo UG. Effect of budesonide in combination with formoterol for reliever therapy in asthma exacerbations: a randomised controlled, double-blind study. Lancet. 2006;368(9537):744-753.

4. Tulic MK, Christodoulopoulos P, Hamid Q. Small airway inflammation in asthma. Respir Res. 2001;2(6):333-339.

5. Burgel PR. The role of small airways in obstructive airway diseases. Eur Respir Rev. 2011;20(119):23-33.

6. Contoli M, Bousquet J, Fabbri LM, et al The small airways and distal lung compartment in asthma and COPD: a time for reappraisal. Allergy. 2010;65(2):141-151.

7. Hamid Q, Song Y, Kotsimbos TC, et al. Inflammation of small airways in asthma. J Allergy Clin Immunol. 1997;100(1):44-51.

8. Carroll N, Cooke C, James A. The distribution of eosinophils and lymphocytes in the large and small airways of asthmatics. Eur Respir J. 1997;10(2):292-300.

9. Wagner EM, Bleecker ER, Permutt S, Liu MC. Direct assessment of small airways reactivity in human subjects. Am J Respir Crit Care Med. 1998;157(2):447-452.

10. Balzar S, Wenzel SE, Chu HW. Transbronchial biopsy as a tool to evaluate small airways in asthma. Eur Respir J. 2002;20(2):254-259.

11. Ueda T, Niimi A, Matsumoto H, et al. Role of small airways in asthma: investigation using high-resolution computed tomography. J Allergy Clin Immunol. 2006;118(5):1019-1025.

12. Dolhnikoff M, da Silva LF, de Araujo BB, et al. The outer wall of small airways is a major site of remodeling in fatal asthma. J Allergy Clin Immunol. 2009;123(5):1090-1097. 
13. The ENFUMOSA Study Group. The ENFUMOSA cross-sectional European multicentre study of the clinical phenotype of chronic severe asthma. European Network for Understanding Mechanisms of Severe Asthma. Eur Respir J. 2003;22(3):470-477.

14. Sorkness RL, Bleecker ER, Busse WW, et al; National Heart, Lung, and Blood Institute Severe Asthma Research Program. Lung function in adults with stable but severe asthma: air trapping and incomplete reversal of obstruction with bronchodilation. J Appl Physiol. 2008;104(2): 394-403.

15. Scichilone N, Morici G, Zangla D, et al. Effects of exercise training on airway closure in asthmatics. $J$ Appl Physiol. 2012;113(5): 714-718.

16. Brown RH, Scichilone N, Mudge B, Diemer FB, Permutt S, Togias A. High-resolution computed tomographic evaluation of airway distensibility and the effects of lung inflation on airway caliber in healthy subjects and individuals with asthma. Am J Respir Crit Care Med. 2001;163(4): 994-1001

17. Fredberg JJ, Jones KA, Nathan M, et al. Friction in airway smooth muscle: mechanism, latch, and implications in asthma. J Appl Physiol. 1996;81(6):2703-2712.

18. Usmani OS, Biddiscombe MF, Barnes PJ. Regional lung deposition and bronchodilator response as a function of beta2-agonist particle size. Am J Respir Crit Care Med. 2005;172(12):1497-1504.

19. Giraud V, Roche N. Misuse of corticosteroid metered-dose inhaler is associated with decreased asthma stability. Eur Respir J. 2002;19(2): 246-251.

20. Ganderton D, Lewis D, Davies R, Meakin B, Brambilla G, Church T. Modulite: a means of designing the aerosols generated by pressurized metered dose inhalers. Respir Med. 2002;96 Suppl D:S3-S8.

21. Lewis DA, Ganderton D, Meakin BJ, Brambilla G. Modulite: a simple solution to a difficult problem. Respiration. 2005;72 Suppl 1:3-5.

22. Chapman KR, Love L, Brubaker H. A comparison of breath-actuated and conventional metered-dose inhaler inhalation techniques in elderly subjects. Chest. 1993;104(5):1332-1337.

23. Lenney J, Innes JA, Crompton GK. Inappropriate inhaler use: assessment of use and patient preference of seven inhalation devices. EDICI. Respir Med. 2000;94(5):496-500.

24. Scichilone N, Contoli M, Paleari D, et al. Assessing and accessing the small airways; implications for asthma management. Pulm Pharmacol Ther. October 13, 2012. [Epub ahead of print.]

25. Korn S, Buhl R. Efficacy of a fixed combination of ciclesonide and formoterol: the EXCITED-study. Respir Med 2012;106(1):57-67.

26. Papi A. Inhaled BDP/formoterol extra-fine combination. Evidence and future perspectives. Pneumologie. 2009;63 Supp1 2:S102-S106. German.

27. Brutsche MH, Brutsche IC, Munawar M, et al. Comparison of pharmacokinetics and systemic effects of inhaled fluticasone propionate in patients with asthma and healthy volunteers: a randomised crossover study. Lancet. 2000;356(9229):556-561.

28. Hauber H, Taha R, Bergeron C, Migounov V, Hamid Q, Olivenstein R. Effects of hydrofluoroalkane and dry powder-formulated corticosteroids on sputum inflammatory markers in asthmatic patients. Can Respir J. 2006;13(2):73-78.

29. Barnes N, Price D, Colice G, et al. Asthma control with extrafine-particle hydrofluoroalkane-beclometasone vs large-particle chlorofluorocarbon-beclometasone: a real-world observational study. Clin Exp Allergy. 2011;41(11):1521-1532.

30. Huchon G, Magnussen H, Chuchalin A, Dymek L, Gonod FB, Bousquet J. Lung function and asthma control with beclomethasone and formoterol in a single inhaler. Respir Med. 2009;103(1): 41-49.

31. Papi A, Paggiaro P, Nicolini G, Vignola AM, Fabbri LM. Beclomethasone/ formoterol vs fluticasone/salmeterol inhaled combination in moderate to severe asthma. Allergy. 2007;62(10):1182-1188.

32. Papi A, Paggiaro PL, Nicolini G, Vignola AM, Fabbri LM. Beclomethasone/formoterol versus budesonide/formoterol combination therapy in asthma. Eur Respir J. 2007;29(4):682-689.
33. Papi A, Nicolini G, Crimi N, et al. Step-down from high dose fixed combination therapy in asthma patients: a randomized controlled trial. Respir Res. 2012;13:54.

34. Scichilone N, Battaglia S, Sorino C, et al. Effects of extra-fine inhaled beclomethasone/formoterol on both large and small airways in asthma. Allergy. 2010;65(7):897-902.

35. Goldin JG, Tashkin DP, Kleerup EC, et al. Comparative effects of hydrofluoroalkane and chlorofluorocarbon beclomethasone dipropionate inhalation on small airways: assessment with functional helical thin-section computed tomography. J Allergy Clin Immunol. 1999;104(6):S258-S267.

36. Cohen J, Douma WR, ten Hacken NH, Vonk JM, Oudkerk M, Postma DS. Ciclesonide improves measures of small airway involvement in asthma. Eur Respir J. 2008;31(6):1213-1220.

37. Hozawa S, Terada M, Hozawa M. Comparison of budesonide/formoterol Turbuhaler with fluticasone/salmeterol Diskus for treatment effects on small airway impairment and airway inflammation in patients with asthma. Pulm Pharmacol Ther. 2011;24(5):571-576.

38. Leach CL, Kuehl PJ, Chand R, Ketai L, Norenberg JP, McDonald JD. Characterization of respiratory deposition of fluticasone-salmeterol hydrofluoroalkane-134a and hydrofluoroalkane-134a beclomethasone in asthmatic patients. Ann Allergy Asthma Immunol. 2012;108(3): 195-200.

39. De Backer W, Devolder A, Poli G, et al. Lung deposition of BDP/ formoterol HFA pMDI in healthy volunteers, asthmatic, and COPD patients. J Aerosol Med Pulm Drug Deliv. 2010;23(3):137-148.

40. Fabbri LM, Nicolini G, Olivieri D, Papi A. Inhaled beclometasone dipropionate/formoterol extra-fine fixed combination in the treatment of asthma: evidence and future perspectives. Expert Opin Pharmacother. 2008;9(3):479-490.

41. Tarsin WY, Pearson SB, Assi KH, Chrystyn H. Emitted dose estimates from Seretide Diskus and Symbicort Turbuhaler following inhalation by severe asthmatics. Int J Pharm. 2006;316(1-2):131-137.

42. Nagel MW, Wiersema KJ, Bates SL, Mitchell JP. Performance of large- and small-volume valved holding chambers with a new combination long-term bronchodilator/anti-inflammatory formulation delivered by pressurized metered dose inhaler. J Aerosol Med. 2002;15(4):427-433.

43. Mariotti F, Sergio F, Acerbi D, Meyer T, Herpich C. Lung deposition of the extra-fine dry powder fixed combination beclomethasone dipropionate plus formoterol fumarate via the NEXT DPI ${ }^{\circledR}$ in healthy subjects, asthmatic and COPD patients. Presented at the European Respiratory Society 21 st Annual Congress, Amsterdam, The Netherlands, September 24-28, 2011.

44. Juniper EF, Price DB, Stampone PA, Creemers JP, Mol SJ, Fireman P. Clinically important improvements in asthma-specific quality of life, but no difference in conventional clinical indexes in patients changed from conventional beclomethasone dipropionate to approximately half the dose of extra-fine beclomethasone dipropionate. Chest. 2002;121(6): $1824-1832$

45. Muller V, Galffy G, Eszes N, et al. Asthma control in patients receiving inhaled corticosteroid and long-acting beta2-agonist fixed combinations. A real-life study comparing dry powder inhalers and a pressurized metered dose inhaler extra-fine formulation. BMC Pulm Med. 2011; 11:40.

46. Allegra L, Cremonesi G, Girbino G, et al. Real-life prospective study on asthma control in Italy: cross-sectional phase results. Respir Med. 2012;106(2):205-214.

47. Brusselle G, Peche R, Van den Brande P, Verhulst A, Hollanders W, Bruhwyler J. Real-life effectiveness of extra-fine beclometasone dipropionate/formoterol in adults with persistent asthma according to smoking status. Respir Med. 2012;106(6):811-819.

48. Takeda T, Oga T, Niimi A, et al. Relationship between small airway function and health status, dyspnea and disease control in asthma. Respiration. 2010;80(2):120-126.

49. Osterberg L, Blaschke T. Adherence to medication. $N$ Engl J Med. 2005;353(5):487-497. 
50. Rubin BK. Inhaled corticosteroids: devices and deposition. Paediatr Respir Rev. 2004;5 Suppl A:S103-S106.

51. Rand CS. Adherence to asthma therapy in the preschool child. Allergy. 2002;57 Suppl 74:48-57.

52. Bender B, Zhang L. Negative affect, medication adherence, and asthma control in children. J Allergy Clin Immunol. 2008;122(3): 490-495.
53. Jentzsch NS, Camargos PA, Colosimo EA, Bousquet J. Monitoring adherence to beclomethasone in asthmatic children and adolescents through four different methods. Allergy. 2009;64(10):1458-1462.

54. Graves MM, Adams CD, Portnoy JM. Adherence in young children with asthma. Curr Opin Allergy Clin Immunol. 2006;6(2):124-127.

55. Bender BG. Depression symptoms and substance abuse in adolescents with asthma. Ann Allergy Asthma Immunol. 2007;99(4):319-324.

\section{Publish your work in this journal}

The Journal of Asthma and Allergy is an international, peer-reviewed open-access journal publishing original research, reports, editorials and commentaries on the following topics: Asthma; Pulmonary physiology; Asthma related clinical health; Clinical immunology and the immunological basis of disease; Pharmacological interventions and
Dovepress

new therapies. Issues of patient safety and quality of care will also be considered. The manuscript management system is completely online and includes a very quick and fair peer-review system, which is all easy to use. Visit http://www.dovepress.com/testimonials.php to read real quotes from published authors.

Submit your manuscript here: http://www.dovepress.com/journal-of-asthma-and-allergy-journal 